\title{
Morphological, Structural, Microhardness and Corrosion Characterisations of Electrodeposited Ni-Mo and Cr Coatings
}

\author{
Pedro de Lima-Neto, * Adriana N. Correia, Gustavo L. Vaz and Paulo N. S. Casciano \\ Departamento de Química Analítica e Físico-Química, Universidade Federal do Ceará, \\ Campus do Pici, Bloco 940, 60455-960 Fortaleza-CE, Brazil
}

\begin{abstract}
A resistência à corrosão de eletrodepósitos de Cr e Ni-Mo e a influencia do tratamento térmico na estrutura cristalográfica, na morfologia e nas propriedades de microdureza foram investigados. As caracterizações foram feitas usando as técnicas de microscopia eletrônica de varredura (SEM), difração de raios X (XRD) e energia dispersiva de raios X (EDX). Os ensaios de corrosão foram feitos à temperatura ambiente, em solução de $\mathrm{NaCl} 10^{-1} \mathrm{~mol} \mathrm{dm}^{-3}$ e usando a técnica de polarização linear potenciodinâmica. O teor de Mo na camada e a eficiência de corrente aumenta com a concentração do íon molibdato no banho de eletrodeposição, enquanto que a morfologia superficial evolui de rugosa e homogênea para trincada com o aumento do teor de Mo na camada. Os ensaios eletroquímicos de corrosão mostram que os eletrodepósitos de $\mathrm{Cr}$ são mais resistentes à corrosão que os eletrodepósitos de Ni-Mo e que todas as camadas estudadas corroem em meio de cloreto. Dentre os eletrodepósitos de Ni-Mo estudados, o de Ni-13Mo foi o que apresentou o comportamento de resistência à corrosão mais nobre. A microdureza do eletrodepósito Ni-13Mo aumenta com o aumento da temperatura de tratamento térmico e está relacionado à formação de fases de $\mathrm{Ni}, \mathrm{Ni}_{4} \mathrm{Mo}$ e NiMo, durante o tratamento térmico. Ni-13Mo é um potencial candidato a substituir o $\mathrm{Cr}$ em aplicações industriais quando a temperatura de operação for maior que $100{ }^{\circ} \mathrm{C}$ e que boas propriedades de microdureza sejam requeridas.
\end{abstract}

The corrosion resistance of electrodeposited $\mathrm{Cr}$ and Ni-Mo coatings and the influence of heat treatment on the crystallographic structure, morphology and microhardness properties were investigated here. The characterisations were carried out using scanning electron microscopy (SEM), X-ray diffraction (XRD) and energy dispersive X-ray analysis (EDX) techniques. Corrosion tests were performed at room temperature in $10^{-1} \mathrm{~mol} \mathrm{dm}{ }^{-3} \mathrm{NaCl}$ solutions and by potentiodynamic linear polarization technique. The Mo content in the layer and current efficiency increased with the molybdate ion concentration in the plating solution, while the surface morphology evolved from rough and homogeneous to cracked surface with the increase of the amount of Mo in the layer. The electrochemical corrosion tests showed that the $\mathrm{Cr}$ coatings have better corrosion resistance than the Ni-Mo coatings in chloride medium and that all the studied coatings corrode in chloride medium. Ni-13Mo coating has the nobler corrosion behavior among the studied Ni-Mo coatings. The microhardness of the Ni-13Mo coatings increased as the annealing temperature increased which is related with the precipitation of $\mathrm{Ni}, \mathrm{Ni}_{4} \mathrm{Mo}$ and NiMo phases during the heat treatment of this coating. Ni-13Mo coating is a potential substitute for chromium coating in industrial applications when operating at temperatures higher than $100{ }^{\circ} \mathrm{C}$ and good microhardness properties are required.

Keywords: Ni-Mo, Cr, electrodeposition, corrosion, heat treatment, microhardness

\section{Introduction}

Hard chromium coating is yet widely used in industrial practice because it presents good corrosion resistant properties. However, due to the environmental and toxicological restrictions involved in the hard chromium industrial electroplating process, which requires the use

*e-mail: pln@ufc.br of the carcinogenic $\mathrm{Cr}^{6+}$ ions, it is increasing the world opposition to the industrial application of this coating. In addition, these restrictions have in recent years directed the researches towards to find new alternative coatings, inserted in the newest concept of the developments of environmental friendly processes. Brooman ${ }^{1,2}$ indicated $\mathrm{Ni}-\mathrm{Mo}$ as a possible candidate to replace the industrial hard chromium coating and the industrial production of these coatings will produce environmentally harmless wastewater. 
Some works reported in the literature were published regarding only the operational electroplating parameters or about the electrodeposition mechanism of the Ni-Mo layer. Podlaha et al. ${ }^{3,4}$ studied the electrodeposition of Ni-Mo coatings on rotating cylinder electrodes and observed that coating composition was influenced by $\mathrm{Ni}^{2+} / \mathrm{Mo}_{2} \mathrm{O}_{4}{ }^{2-}$ ratio in the plating solution and that Mo content was strongly influenced by the convective transport. Pavlov et al. ${ }^{5}$ have presented a wide investigation about the electroplating of Ni-Mo alloys from ammonium citrate baths containing intermediate valence molybdenum compounds and they evaluated the electrolysis under different operational conditions, such as $\mathrm{pH}$ and temperature. The effect of differing molybdenum compounds (oxidation degrees of $+6,+5$, and +3 ) on the alloy formation makes possible controlling the alloy composition and the current efficiency by varying the concentration ratio of molybdenum in different states of the oxidation. The prospects for the formation of deposits of adequate quality with the current efficiency of nearly $80 \%$ were demonstrated.

Kuznetsov et al. ${ }^{67}$ investigated the effect of concentration of ammonia and citrate ions on the electrodeposition of a Ni-Mo alloys. The experimental data indicated an incomplete reduction of molybdate ions accelerated by ammonium ions forming intermediate products adsorbed on the electrode surface.

The electrodeposition of Ni-Mo was also performed using pulsed techniques. Yagi et al. ${ }^{8}$ carried out a study using alternating pulse electrolysis and they have demonstrated that molybdenum can be electrodeposited on a nickel substrate electrochemically using an aqueous $\mathrm{Mo}(\mathrm{VI})$ solution. Ni-Mo alloy with different compositions can be obtained without having to prepare various plating solutions by controlling the pulse parameters. Marlot et al. ${ }^{9}$ showed that at sufficiently short pulse periods, the Mo content was higher than in dc plating condition.

On the other hand, little attention is given in the literature about the physical characterization of electrodeposited Ni-Mo coatings. ${ }^{10-13}$ Donten et al. ${ }^{10}$ performed the electrodeposition of Ni-Mo alloys from pyrophosphate baths and they showed that the use of this complexing agent resulted in the removal of bumps, spheres and cracks from the Ni-Mo alloy surface. The amorphous/nanocrystalline structures appeared for the deposits content Mo higher than $20 \%$ in atom while that obtained with the lower amount of Mo were crystalline. Chassaing et al. ${ }^{11}$ studied the electrodeposition of Ni-Mo nanocrystalline layers using direct current in citrate-ammonium plating solutions and found that the layers exhibited microhardness comparable with the hard chromium coating ( $c a .800$ Vickers) and also presented corrosion current higher than Hastelloy B alloy.
These authors also found that the alloys with Mo content high than 30 wt.\% were amorphous. Sanches et al. ${ }^{12,13}$ studied the electrodeposition of Ni-Mo in citrate medium at pH 4 and obtained crystalline Ni-Mo coating and, using XPS technique, they detected the presence of multivalent molybdenum oxide or hydroxide.

Furthermore, nothing it is known about the influence of annealing temperature on the crystal structure, coating morphology and hardness properties of the Ni-Mo coatings. In addition, despite many authors quote the good corrosion resistance properties of the electrodeposited Ni-Mo coatings at room temperature, relatively little reports about this subject are found in the literature. ${ }^{11}$ Thus, this work was carried out aiming to perform a comparative study of the corrosion resistance of both electrodeposited $\mathrm{Cr}$ and Ni-Mo coatings in chloride medium and also to evaluate the influence of thermal treatments on corrosion resistance, on crystal structure and on microhardness properties of these coatings.

\section{Experimental}

\section{Electrodeposition}

Solutions were prepared from analytical grade purity chemicals dissolved in water purified with a Millipore Milli-Q system. Ni-Mo coatings were electrodeposited on disc-shaped $\mathrm{Cu}$ substrate embedded in epoxy resin, with a geometric area of approximately $2 \mathrm{~cm}^{2}$ of exposure. The electrodepositions were performed in a single-compartment Pyrex $^{\circledast}$ glass cell with a Teflon ${ }^{\circledast}$ cover containing holes to fix the $\mathrm{Cu}$ cathode and the platinum mesh anode. Prior to the alloy plating, the $\mathrm{Cu}$ surfaces were polished with 240, 400 and $600 \mathrm{SiC}$ emery paper, degreased in a hot $\mathrm{NaOH}$ solution, rinsed in distilled water, etched in $15 \% \mathrm{HCl}$ solution and, lastly, rinsed with distilled water. Table 1 gives the composition of the Ni-Mo plating solutions and the operational parameters used to electrodeposit Ni-Mo

Table 1. Composition of the baths utilized in the electrodeposition (pH 9)

\begin{tabular}{lcccc}
\hline Reagent & \multicolumn{4}{c}{ Concentration / $\left(\mathrm{mol} \mathrm{dm}^{-3}\right)$} \\
\cline { 2 - 5 } & bath 1 & bath 2 & bath 3 & bath4 \\
\hline $\mathrm{Na}_{2} \mathrm{MoO}_{4} \cdot 2 \mathrm{H}_{2} \mathrm{O}$ & 0.010 & 0.020 & 0.040 & 0.100 \\
$\mathrm{NiSO}_{4} \cdot \mathrm{H}_{2} \mathrm{O}$ & & & 0.170 & \\
$\mathrm{Na}_{3} \mathrm{Cit} \cdot 2 \mathrm{H}_{2} \mathrm{O}$ & & & 0.200 & \\
\hline
\end{tabular}

Operational deposition parameters:

pH 9 (adjusted with ammonia)

Plating temperature $=$ room temperature $\left(\mathrm{ca} .27^{\circ} \mathrm{C}\right)$

Electrodeposition current density $=50 \mathrm{~mA} \mathrm{~cm}{ }^{-2}$

Total charge deposition $=50 \mathrm{C}$ and $1,500 \mathrm{C}$ 
coatings. The Cr layers were deposited under galvanostatic control at $135 \mathrm{~mA} \mathrm{~cm}{ }^{-2}$ from an industrial plating bath containing $0.5 \mathrm{~mol} \mathrm{dm}^{-3} \mathrm{CrO}_{3}$ and $0.02 \mathrm{~mol} \mathrm{dm}^{-3} \mathrm{H}_{2} \mathrm{SO}_{4}$ at $60{ }^{\circ} \mathrm{C}$ with a total charge of $250 \mathrm{C}$.

\section{Heat treatment}

As-electrodeposited $\mathrm{Cu} / \mathrm{Ni}-\mathrm{Mo}$ and $\mathrm{Cu} / \mathrm{Cr}$ samples were annealed in a $\mathrm{N}_{2}$ atmosphere at $100,200,400$ and $600{ }^{\circ} \mathrm{C}$, using a heating rate of $10^{\circ} \mathrm{C} \mathrm{min}^{-1}$ from room temperature to the desired temperature plateau, where they were held for $1 \mathrm{~h}$ and then cooled to room temperature.

\section{Physical and chemical characterization}

The surface and cross section morphologies of the electrodeposits were analyzed by a Philips XL-30 SEM. The SEM cross section allowed the determination of the coating thickness. The coating composition was analyzed by EDX apparatus attached to the SEM. The coating crystal phase structure was analyzed by XRD using a Philips model $\mathrm{X}$ 'Pert pro diffractometer with $\mathrm{Cu} \mathrm{K} \alpha$ radiation $(\lambda=1.54 \AA)$ at $40 \mathrm{KV}$ and $40 \mathrm{~mA}$ and an incident angle of $3^{\circ}$. The main peaks observed in the diffractograms were compared with XRD data from the Joint Committee of Powder Diffraction Standards (JCPDS). Microhardness measurements were carried out using Shimadzu, model HMV-2-Series, microhardeness tester with a diamond pyramid indenter at a load of $10 \mathrm{~g}$, which was maintained for $30 \mathrm{~s}$. An average of 10 readings was taken to obtain the hardness values of the coatings. To prevent the substrate from affecting the microhardness measurements, samples were obtained with a total electrodeposition charge of 1,500 C.

\section{Corrosion tests}

The corrosion behaviour of as-electrodeposited Ni-Mo and $\mathrm{Cr}$ coatings were evaluated by potentiodynamic linear polarization (PLP) technique with scan rate of $1 \mathrm{mV} \mathrm{s}^{-1}$ in $0.1 \mathrm{~mol} \mathrm{dm}{ }^{-3} \mathrm{NaCl}$ aqueous solutions with a natural $\mathrm{pH}$ of 6.5. A potenciostato/galvanostato AUTOLAB PGSTAT 30, linked to a PC microcomputer and controlled by the GPES and FRA software, was used for the acquisition of the electrochemical data.

\section{Results and Discussion}

\section{EDX analyses}

The influence of the $\mathrm{MoO}_{4}{ }^{2-}$ ion concentration on the Mo content in the layer and current efficiency is shown in

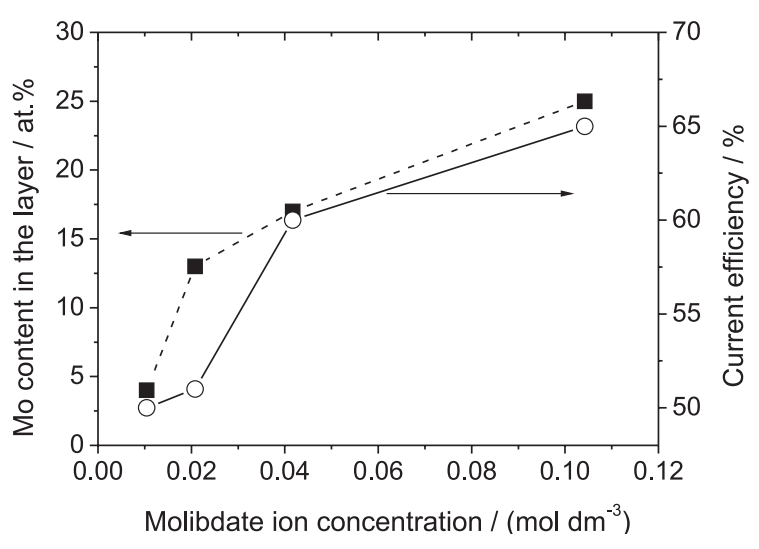

Figure 1. Influence of the $\mathrm{MoO}_{4}{ }^{2-}$ ion concentration on the Mo content in the layers and on the current efficiency.

Figure 1. The current efficiency was calculated from the equation (1), where $\eta_{c}$ is the cathodic current efficiency, $t_{E}$ is the experimental thickness determined from SEM cross section analyses and $t_{\mathrm{T}}$ is the thickness calculated from Faraday's laws.

$\eta_{\mathrm{c}}=\left(\mathrm{t}_{\mathrm{E}} / \mathrm{t}_{\mathrm{T}}\right) \times 100$

It can be observed in this figure that the molybdenum content in the layer and the current efficiency rise with the molybdate ion concentration in the plating solution. This behaviour is in close agreement the results reported in the literature by Marlot et al., ${ }^{9}$ which electrodeposited Ni-Mo layers in ammonia-citrate electrolyte applying pulse potential and in similar concentration range of molybdate ion to that used in this investigation. Similar dependence between the amount of Mo in the layer and the molybdate ion concentration was also observed by Donten et al. ${ }^{10}$ in pyrophosphate plating bath using normal direct current. Marlot et al. ${ }^{9}$ pointed out that the observed dependence between the amount of Mo in the layer and the molybdate ion concentration in the plating solution suggests that the codeposition process is limited by diffusion of the molybdate ion.

\section{SEM characterization of the as-electrodeposited coatings}

The surface and cross sections morphologies of the as-electrodeposited Ni-Mo coatings were analyzed by SEM and selected images are displayed in Figure 2. The surface SEM images show that the coatings obtained from the plating solutions containing $0.01 \mathrm{~mol} \mathrm{dm}^{-3}$ and $0.02 \mathrm{~mol} \mathrm{dm}^{-3}$ of molybdate ions (baths 1 and 2) are rough and homogeneous, without defects from top to bottom and with some nuclei distributed on the surface (Figures 2a-2d), while those obtained from the plating solution containing 

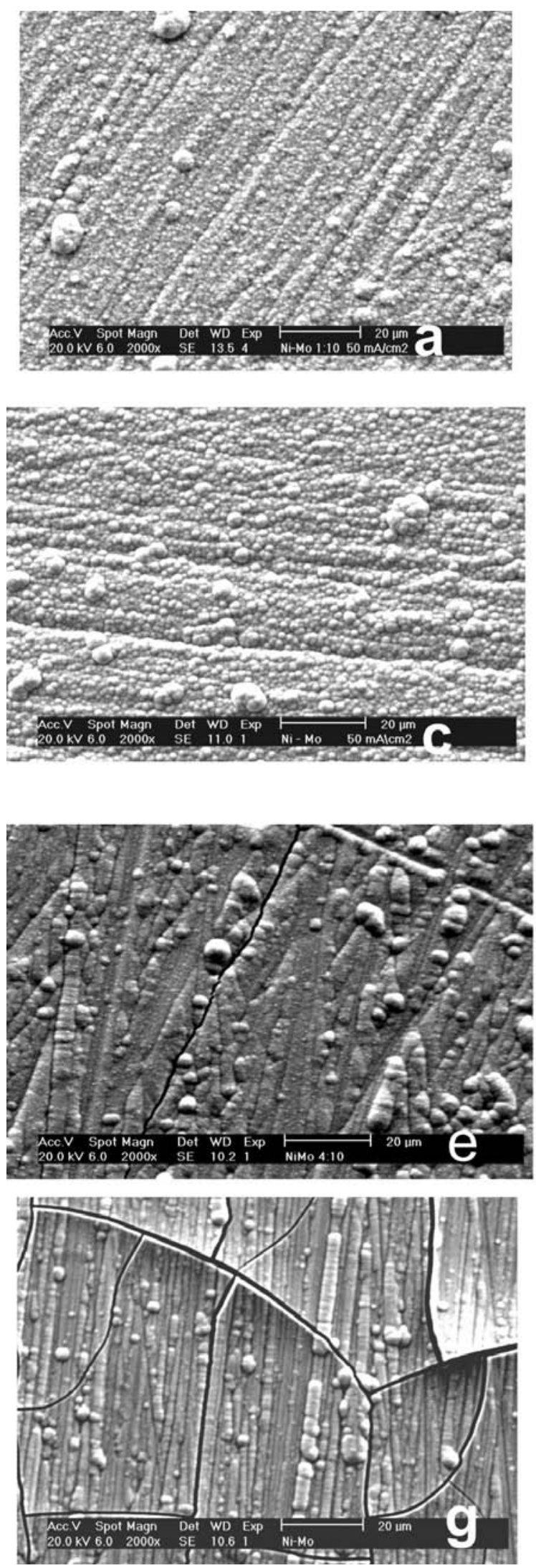
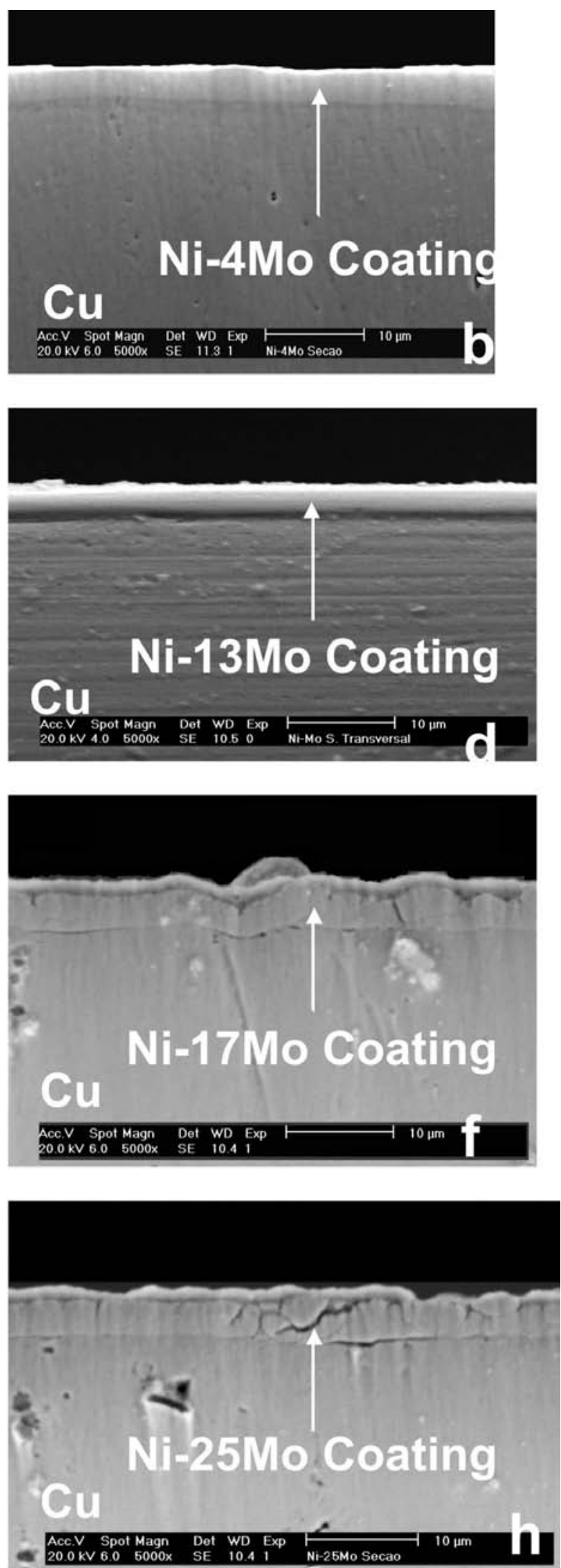

Figure 2. SEM images showing the surface and cross section morphologies of the Ni-Mo coatings obtained at $50 \mathrm{~mA} \mathrm{~cm}{ }^{-2}$ : Ni-4Mo obtained from bath containing $0.01 \mathrm{~mol} \mathrm{dm}^{-3} \mathrm{MoO}_{4}^{2-}(\mathrm{a}, \mathrm{b})$; Ni-13Mo obtained from bath containing $0.02 \mathrm{~mol} \mathrm{dm}{ }^{-3} \mathrm{MoO}_{4}^{2-}$ (c, d); Ni-17Mo obtained from bath containing $0.04 \mathrm{~mol} \mathrm{dm}^{-3} \mathrm{MoO}_{4}{ }^{2-}(\mathrm{e}, \mathrm{f})$ and $\mathrm{Ni}-25 \mathrm{Mo}$ obtained from bath containing $0.1 \mathrm{~mol} \mathrm{dm}^{-3} \mathrm{MoO}_{4}^{2-}(\mathrm{g}, \mathrm{h})$. 
$0.04 \mathrm{~mol} \mathrm{dm}^{-3}$ and $0.10 \mathrm{~mol} \mathrm{dm}{ }^{-3}$ of molybdate ions (baths 3 and 4 ) are cracked (Figures $2 \mathrm{e}$ and $2 \mathrm{~g}$ ), which cross from the surface until the substrate (Figures $2 \mathrm{f}$ and $2 \mathrm{~h}$ ). The presence of the observed nuclei on the Ni-Mo surface can be explained as a consequence of the growth of secondary nuclei on top of the layer that were formed in the primary nucleation phase. In addition, some polyhedral grains can be observed, suggesting that they are formed by several nuclei. Cracked morphologies were also observed by Chassaing et al. ${ }^{11}$ for Ni-Mo coatings containing Mo higher than $30 \mathrm{wt} . \%$, which were electrodeposited from citrate bath and under force hydrodynamic operational conditions. The appearance of the cracks is explained as being caused by relaxation of internal tensile stress in the coating.

The surface and cross-sectional SEM micrographs of the Cr coating are shown in Figure 3. The surface morphology of the $\mathrm{Cr}$ coating is characterised by a dendrite microstructure (Figure 3a), while the cross-section micrograph reveals a homogeneous and compact coating without microcracks (Figure 3b). It is well known that a crack-free or a cracked morphology of electrodeposited $\mathrm{Cr}$ coating can be obtained by proper adjustment of the plating conditions,${ }^{14}$ and the non-cracked morphologies shown in these micrographs are typical for the electrodeposited $\mathrm{Cr}$ coatings obtained under the operational condition used in this work. Yun et al.,$^{15}$ using similar operational conditional, also obtained a non-cracked electrodeposited $\mathrm{Cr}$ coating. However, SEM images showed that the surface morphology was compact and dendrites were not observed. ${ }^{15}$
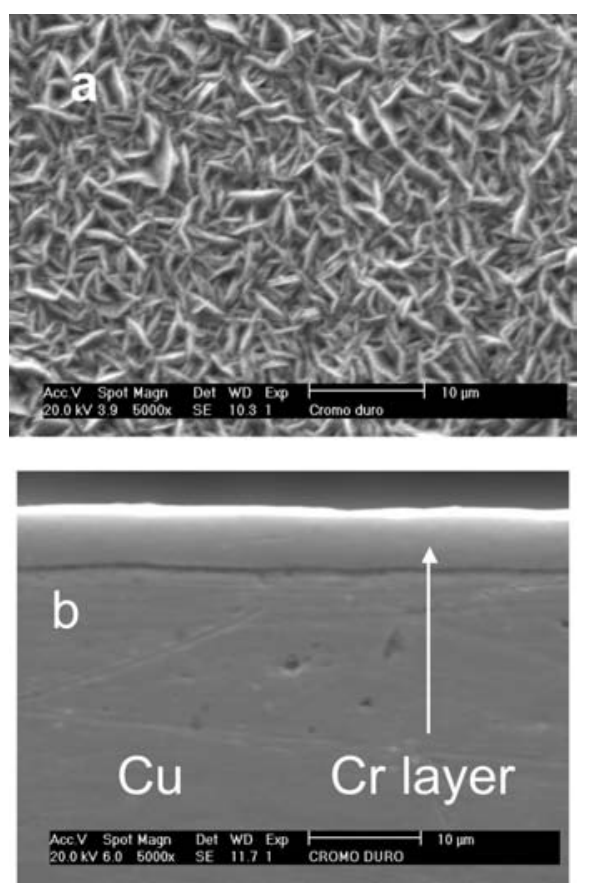

Figure 3. SEM images showing the surface (a) and the cross-section (b) morphologies of the $\mathrm{Cr}$ coating.

\section{Electrochemical corrosion tests for the as-electrodeposited} and as-annealed samples

Potentiodynamic polarization curves for the aselectrodeposited Ni-Mo and $\mathrm{Cr}$ coatings in $0.1 \mathrm{~mol} \mathrm{~L}^{-1} \mathrm{NaCl}$ solutions are shown in Figure 4. This figure shows that the $\mathrm{Cr}$ coating has the noblest corrosion potential, which is $-0.328 \mathrm{~V}$. Among the Ni-Mo coatings, the nobler corrosion potential is presented by the Ni-13Mo coating, which is $-0.362 \mathrm{~V}$. The experimental value of the corrosion potential for the Ni-Mo coatings are in close agreement with those reported in the literature, ${ }^{11}$ while the corrosion potential of the $\mathrm{Cr}$ coating is about $0.15 \mathrm{~V}$ more positive than that reported by others authors. ${ }^{15}$ This difference in the corrosion potential it is explained as to be related to the different surface morphology present by the electrodeposited $\mathrm{Cr}$ in this work (Figure 3a) compared to the surface morphology of the electrodeposited $\mathrm{Cr}$ coating reported in the literature. ${ }^{15}$

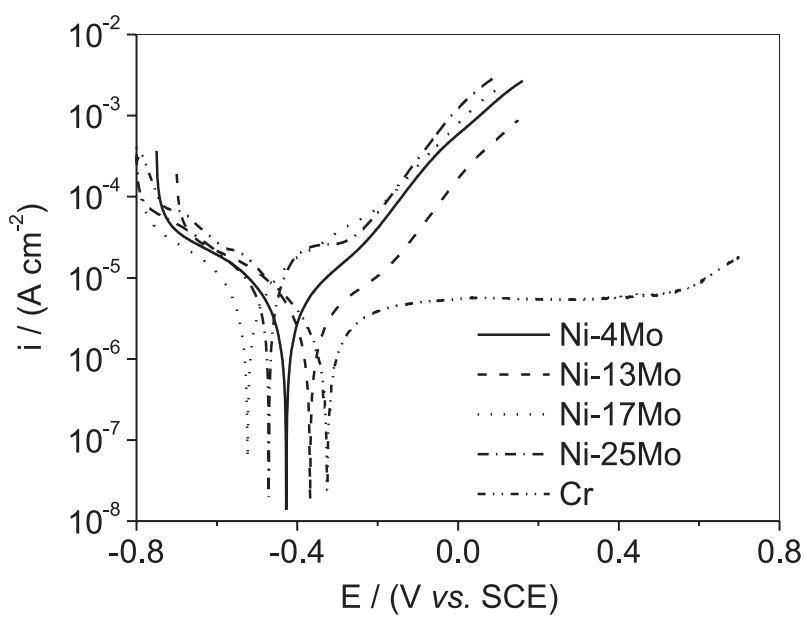

Figure 4. Potentiodynamic polarization curves obtained in $0.1 \mathrm{~mol} \mathrm{dm}^{-3}$ $\mathrm{NaCl}$ solution for the as-electrodeposited $\mathrm{Ni}-\mathrm{Mo}$ and $\mathrm{Cr}$ coatings.

In addition, a current plateau is observed in the range from $-0.048 \mathrm{~V}$ to $0.483 \mathrm{~V}$ in the polarization curve of the $\mathrm{Cr}$ coating, followed by an increase in the current for higher applied potentials, while an increase in the anodic current with the applied potential is observed in the anodic branch of all the studied Ni-Mo coatings. For the case of the $\mathrm{Cr}$ costing, the plateau is associated with the formation of surface films that can, initially, block the dissolution of the coating and the increase in current that follows the current plateau is related to the breakdown of said surface film, leading to the dissolution of the coating. For the Ni-Mo coatings, the increase of the anodic current is associated with the uniform dissolution of these coatings. These results demonstrate that the all coatings corrode in chloride medium. Finally, these curves also show that the 
cracked coatings present the worse corrosion behavior, indicating that the cracks are deleterious for the corrosion resistance property.

From the results showed in Figure 4, Ni-13Mo coating was selected to be compared with the $\mathrm{Cr}$ coating in order to evaluate the influence of the heat treatment in the corrosion resistance and microhardness properties, because it was previously shown that this proprieties deteriorate when $\mathrm{Cr}$ coating is heat treated, even at $100{ }^{\circ} \mathrm{C} \cdot{ }^{16,17}$ Figure 5
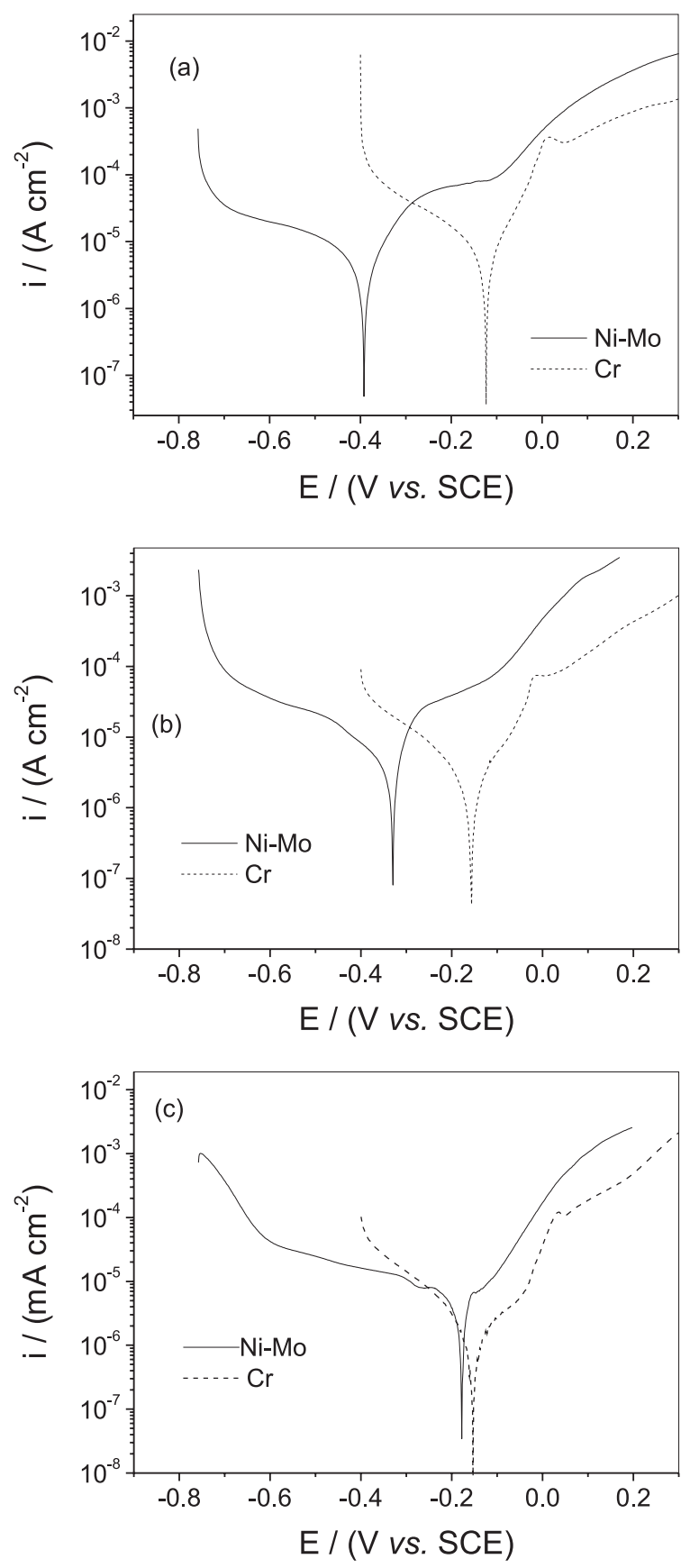

Figure 5. Potentiodynamic polarization curves obtained in $0.1 \mathrm{~mol} \mathrm{dm}^{-3}$ $\mathrm{NaCl}$ solution for the $\mathrm{Ni}-\mathrm{Mo}$ and $\mathrm{Cr}$ coatings annealed at $200{ }^{\circ} \mathrm{C}$ (a), $400{ }^{\circ} \mathrm{C}(\mathrm{b})$ and $600{ }^{\circ} \mathrm{C}$ (c). shows the polarization curves for the $\mathrm{Ni}-13 \mathrm{Mo}$ and $\mathrm{Cr}$ coatings annealed at the selected temperatures. This figure shows that both as-annealed Ni-Mo and as-annealed $\mathrm{Cr}$ coatings present uniform dissolution in chloride medium. In addition, this figure also shows that the as-annealed $\mathrm{Cr}$ coatings present superior corrosion resistance than the asannealed Ni-13Mo coatings, since its corrosion potential is nobler and their anodic current densities are lesser than those presented by the as-annealed $\mathrm{Ni}-13 \mathrm{Mo}$ coatings.

\section{Microhardness measurements and XRD characterization}

The evolution of the microhardness of the Ni-13Mo and $\mathrm{Cr}$ coatings with the annealing temperature is shown in Figure 6. The as-electrodeposited Ni-13Mo and Cr coatings have microhardness about of 287 and $855 \mathrm{Hv}$, respectively. Additionally, the microhardness of the Ni-13Mo increases and the microhardness of the $\mathrm{Cr}$ coating decreases with the annealing temperature. Similar trend was previously observed for Ni-W-P ${ }^{16}$ and Ni-Cr-P. ${ }^{17}$

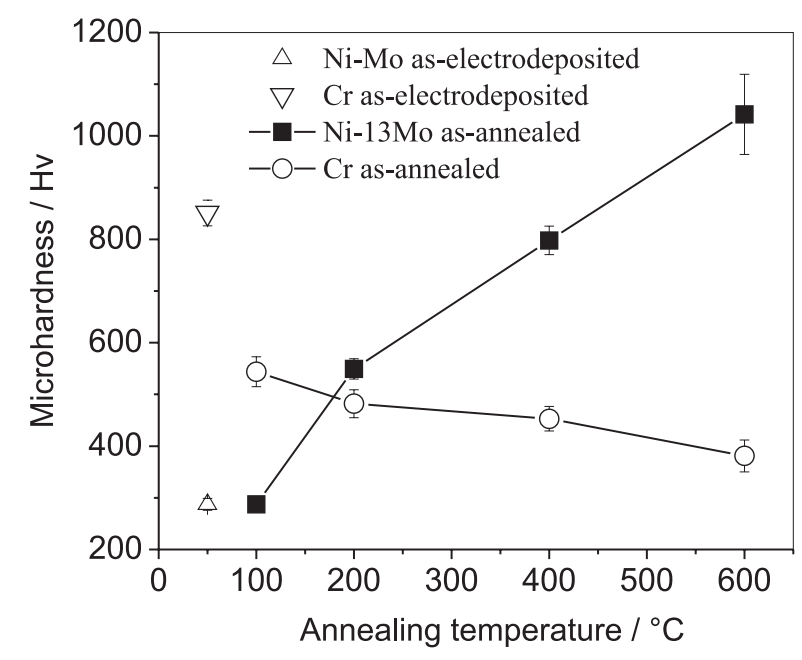

Figure 6. Microhardness for the as-electrodeposited Ni-13Mo and $\mathrm{Cr}$ coatings and as-annealed at different temperatures.

In order to understand the microhardness behaviour of the Ni-Mo coatings with the annealing temperature, X-ray diffractograms were obtained for annealed samples and the diffractograms are shown in Figure 7. For the aselectrodeposited Ni-13Mo coating (Figure 7a), two broad peaks can be observed in the diffractograms at $2 \theta$ angles of about $45^{\circ}$ and $51^{\circ}$. These broad peaks can be related to the nickel diffraction peaks, and none are related to the molybdenum. This result is in close accordance with those already published in the literature for the electrodeposited Ni-Mo coatings. ${ }^{10,11}$ The X-ray diffractograms of the Ni-Mo coating electrodeposited from pyrophosphate bath ${ }^{10}$ or from citrate bath ${ }^{11}$ indicated the formation of $\mathrm{Ni}-\mathrm{Mo}$ solid 


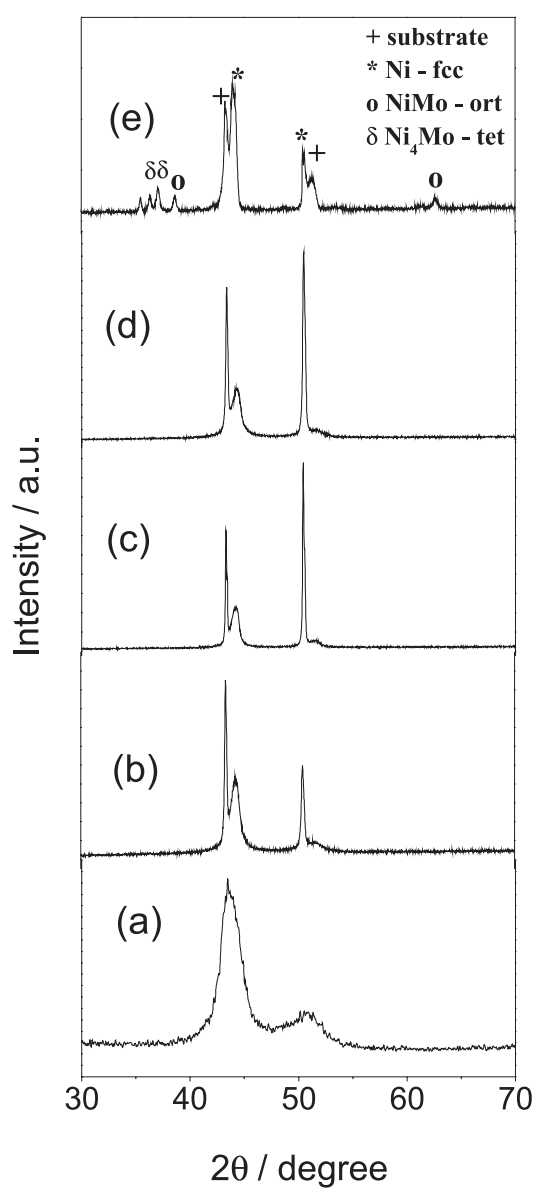

Figure 7. X-ray diffractograms for the as-electrodeposited Ni-13Mo coatings (a) and for the $\mathrm{Ni}-13 \mathrm{Mo}$ coatings annealed at: $100{ }^{\circ} \mathrm{C}$ (b), $200{ }^{\circ} \mathrm{C}(\mathrm{c}), 400{ }^{\circ} \mathrm{C}(\mathrm{d})$ and $600{ }^{\circ} \mathrm{C}(\mathrm{e})$.

solution, with the diffraction peaks being sharp at the lower content of Mo (up to 12 wt.\%) and broad for higher amount of Mo, showing that with the increase of the amount of Mo the layer becomes amorphous. Chassaing et al. ${ }^{11}$ also showed by transmission electron micrographs the same solid solution with the grain size ranging between 4 and $17 \mathrm{~nm}$ (average $5 \mathrm{~nm}$ ), indicating that the electrodeposited Ni-Mo alloy is almost amorphous. Thus, the absence of peaks related to Mo in the diffractogram of the Ni-13Mo can be explained by the formation of a Mo solid solution in nickel that consists of molybdenum atoms substitutionally dissolved in nickel. In addition, the diffractograms of the as-electrodeposited Ni-13Mo is also similar with that presented by Sriraman et al. ${ }^{18}$ for the electrodeposited Ni-W coatings. From these authors, the broadened peaks observed in Figure 7a are explained as due to the reduction in the crystallite size of the alloys, with an increase in the amount of alloying molybdenum element with Ni-Mo crystallites distributed in the Ni-Mo amorphous matrix. The amorphous phase is formed during the electrodeposition process, either due to the formation of mutually incoherent particles that are too small to permit the crystalline phase to be formed or atoms that do not bond together in the arrangement required for crystalline long-range order. ${ }^{19}$ Finally, the diffractograms of the as-electrodeposited coating suggests that Ni-13Mo coating consists of two phases: the crystalline phase and the amorphous phase.

The diffractograms of the annealed samples show that the thermal treatment leads to the precipitation of new crystalline phases, even when annealed at $100{ }^{\circ} \mathrm{C}$. It is possible to observe that with the increase in the annealing temperature up to $400{ }^{\circ} \mathrm{C}$ the peaks with the $2 \theta$ angle of about $45^{\circ}$ and $51^{\circ}$ are better defined and that the relative intensity of the peak at $51^{\circ}$ rises with the annealing temperature. These results suggest the increase of the annealing temperature up to $400{ }^{\circ} \mathrm{C}$, Ni phases precipitate on the Ni-Mo amorphous matrix. The increase of the $\mathrm{Ni}$ peak intensity corresponds to an increase in the grain size with the annealing temperature. For the sample heat treated at $600{ }^{\circ} \mathrm{C}$, new characteristic peaks are observed in the diffractograms which are associated with the precipitation of the $\mathrm{Ni}$, NiMo and $\mathrm{Ni}_{4} \mathrm{Mo}$ phases. Just as the crystallographic structure can arise from the amorphous structure with the increase of the annealing temperature, the formation of $\mathrm{NiMo}$ and $\mathrm{Ni}_{4} \mathrm{Mo}$ phases after heat treatment at $600{ }^{\circ} \mathrm{C}$ may be explained by a separation of the these crystals phases during the heat treatment at this temperature from the amorphous phase.

From the X-ray analyses, the behaviour of the microhardness with the annealing temperature for the Ni-Mo coatings is explained due to the fact that with the increase of the annealing temperature occurs an increasing in the number of crystals separated out, and the new crystal phases that formed during the heat treatment, favouring an increase in microhardness. Thus, as the annealing temperature increases, $\mathrm{Ni}, \mathrm{Ni}_{4} \mathrm{Mo}$ and $\mathrm{NiMo}$ phases precipitate leading to an increase in the microhardness of the Ni-13Mo coating.

As previously reported, ${ }^{16,17}$ the XRD diffractograms of annealed $\mathrm{Cr}$ coatings from 100 to $600{ }^{\circ} \mathrm{C}$, were identical to the diffractogram obtained for the as-electrodeposited Cr coating sample. All the XRD diffractograms displayed a single characteristic peak at $2 \theta=65^{\circ}$ for the $\mathrm{Cr}$ (110) reflection.

\section{SEM characterisation of the as-annealed samples}

Figure 8 shows the SEM micrographs of the Ni-13Mo coating after heat treatment at temperatures applied in this study. It can be observed that non significant changes in the surface morphology in response to the increase in the 

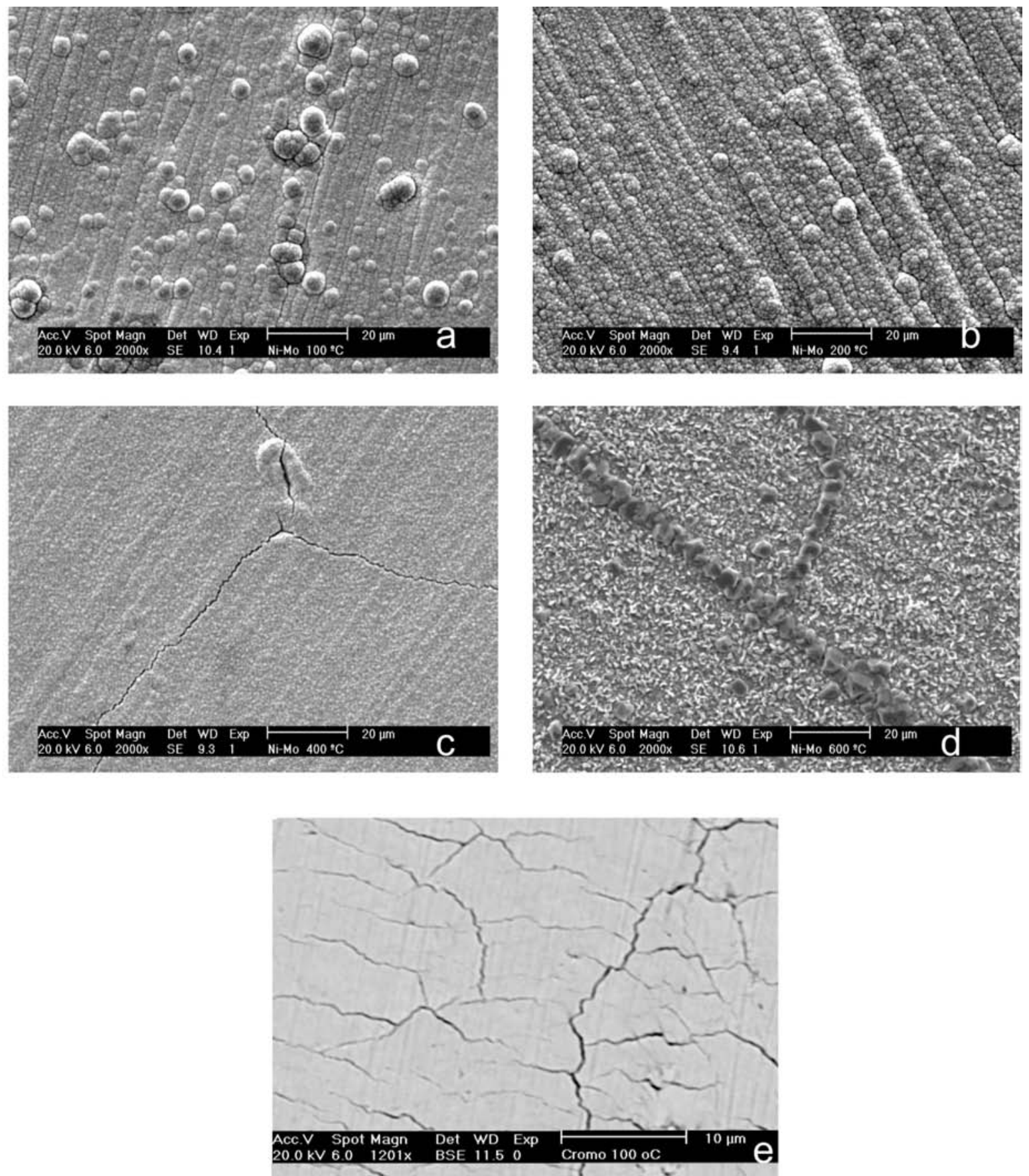

Figure 8. SEM micrographs of Ni-13Mo coating annealed at $100{ }^{\circ} \mathrm{C}(\mathrm{a}), 200^{\circ} \mathrm{C}(\mathrm{b}), 400{ }^{\circ} \mathrm{C}(\mathrm{c})$ and $600{ }^{\circ} \mathrm{C}(\mathrm{d})$ and of the $\mathrm{Cr}$ coating annealed at $100{ }^{\circ} \mathrm{C}(\mathrm{e})$.

annealing temperature for samples annealed up to $200{ }^{\circ} \mathrm{C}$ (Figure 8a and 8b) in comparison with that observed for the as-electrodeposited Ni-13Mo coatings (Figure 2a-2d). Cracks were observed on the Ni-13Mo coating annealed at $400{ }^{\circ} \mathrm{C}$ and crystals can be seen for the sample annealed at $600{ }^{\circ} \mathrm{C}$ which corresponding to phase that precipitated at this temperature. Cracks are also seen for as-annealed $\mathrm{Cr}$ coatings, even when heat treated at $100^{\circ} \mathrm{C}$. The presence of these cracks in the as-annealed samples is caused by residual stress due to the stress relief during the annealing process.

\section{Conclusion}

Ni-Mo coatings were obtained by electrodeposition using direct current and the Mo content in the layer and current efficiency increased with the molybdate ion concentration in the plating solution. The surface morphology evolved from rough and homogeneous to cracked surface with the increase of the amount of Mo in the layer. The electrochemical corrosion tests showed that the $\mathrm{Cr}$ coatings have better corrosion resistance than 
the Ni-Mo coatings in chloride medium and the all the studied coatings corrode in chloride medium. The Ni-13Mo coating is the nobler among the studied Ni-Mo coatings. The microhardness of the Ni-Mo coatings increased as the annealing temperature increased which is related with the precipitation of $\mathrm{Ni}, \mathrm{Ni}_{4} \mathrm{Mo}$ and $\mathrm{NiMo}$ phases were during heat treatment of the Ni-13Mo coating. Ni-13Mo coating is a potential substitute for chromium coating in industrial applications when operating at temperatures higher than $100{ }^{\circ} \mathrm{C}$ and good microhardness properties are required.

\section{Acknowledgments}

The authors thank to Conselho Nacional de Desenvolvimento Científico e Tecnológico (CNPq) and Coordenadoria de Aperfeiçoamento de Pessoal de Nível Superior (CAPES), Brazil, for financial assistance.

\section{References}

1. Brooman, E. W.; Metal Finish. 2000, 98:7, 38 and references cited therein.

2. Brooman, E. W.; Metal Finish. 2000, 98:8, 39 and references cited therein.

3. Podlaha, E. J.; Landolt, L.; J. Electrochem. Soc. 1996, 143, 885.

4. Podlaha, E. J.; Matiosz, M.; Landolt, L.; J. Electrochem. Soc. 1996, 143, 893.

5. Pavlov, M. P.; Morozova, N. V.; Kudryavtsev, V. N.; Prot. Met. 2007, 43, 459.

6. Kuznetsov, V. V.; Pavlov, M. R.; Zimakov, D. I.; Chepeleva, S. A.; Kudryavtsev, V. N.; Russ. J. Electrochem. 2004, 40, 813.
7. Kuznetsov, V. V.; Pavlov, M. R.; Chepeleva, S. A.; Kudryavtsev, V. N.; Russ. J. Electrochem. 2005, 41, 83.

8. Yagi, S.; Kawakami, A.; Murase, K.; Awakura, Y.; Electrochim. Acta 2007, 52, 6041.

9. Marlot, A.; Kern P.; Landolt, D.; Electrochim. Acta 2002, 48, 29.

10. Donten, M.; Cesiulis, H.; Stojek, Z.; Electrochim. Acta 2005, 50, 1405.

11. Chassaing, E.; Portail, N.; Levy, A. F.; Wang, G.; J. Appl. Electrochem. 2004, 34, 1085.

12. Sanches, L. S.; Domingues, S. H.; Marino, C. E. B.; Mascaro, L. H.; Electrochem. Comum. 2004, 6, 543.

13. Sanches, L. S.; Domingues, S. H.; Marino, C. E. B.; Mascaro, L. H.; J. Braz. Chem. Soc. 2003, 14, 556.

14. Dubpernell, G. In Modern Electroplating; Lowenheim, F. A., ed.; $3^{\text {rd }}$ ed., Wiley-Interscience Publication: New York, 1974.

15. Yun, H. J.; Dulal, S. M. S. I.; Shin, C. B.; Kim, C. K.; Electrochim. Acta 2008, 54, 370.

16. de Lima-Neto, P.; da Silva, G. P.; Correia, A. N.; Electrochim. Acta 2006, 51, 4928.

17. de Lima-Neto, P.; Correia, A. N.; da Silva, G. P.; J. Braz. Chem. Soc. 2006, 17, 1419.

18. Sriramam, K. R.; Raman, S. G. S.; Seshadri, S. K.; Mater. Sci. Eng., A 2006, 418, 303.

19. He, F.; Yang, J.; Lei, T.; Gu, C.; Appl. Surf. Sci. 2007, 253, 7591.

Submitted: September 11, 2009

Published online: July 20, 2010 